Itepa: Jurnal Ilmu dan Teknologi Pangan,

Agus Slamet Duniaji dan I Ketut Suter/Itepa 10 (4) 2021 746-752

ISSN : 2527-8010 (Online)

\title{
Pengujian Kandungan Residu Pestisida Pada Tanaman Sayuran Di Kabupaten Badung Dengan Kartu Pendeteksi Pestisida (Pesticide Detection Cards) Dan Gas Chromatography Mass Spectrophotometry
}

\author{
Agus Selamet Duniaji ${ }^{1 *}$ dan I Ketut Suter ${ }^{1}$ \\ Program Studi Teknologi Pangan, Fakultas Teknologi Pertanian, Universitas Udayana \\ Kampus Bukit Jimbaran, Badung-Bali \\ *Penulis korespondensi: Agus Selamet Duniaji, Email: aduniaji@unud.ac.id
}

\begin{abstract}
Abstrak
Pesticides are chemical substances used to control various pests and diseases. In the field, synthetic pesticides are widely used and their use is not controlled and exceeds the permitted threshold according to the Minister of Agriculture No: 88 Permentan/PP.340/12/2011. The purpose of this study was to determine the content of pesticide residues in vegetables cultivated in Badung district. A total of 16 types of vegetables with 32 samples were tested for pesticide residues of organophosphorus and organochlorine groups (Diazinon, chlorphyrifos and Profenopos) on vegetable crops in Badung district. Qualitative testing was carried out with pesticide detection cards (Pesticide Detection Cards) and then samples contaminated with pesticides were continued by testing using Gas Chromatography Mass Spectrophotometry (GC MS) / The test results showed that as many as 30 samples of vegetables $(93.75 \%)$ did not contain diazinon and as many as 2 samples (6.25\%) containing diazinon, namely chinese cabbagge sample 1 of $0.015 \mathrm{ppm}$ and chinese cabbagge of sample 2 of 0.024 ppm. A total of 29 samples of vegetables (90.63\%) did not contain much chlorphyrifos and as many as 3 samples $(9.37 \%)$ contained chlorphyrifos pesticide residues. A total of 30 samples $(93.75 \%)$ contained profenofos and 2 samples of vegetables $(6.25 \%)$ contained profenofos pesticide residues in the mustard greens sample 1 and chicory sample 2 were $0.048 \mathrm{ppm}$ and 0.029 ppm, respectively. According to PERMENTAN No: 88 /Permentan/PP.340/12/2011, from the results of this test, all samples were below the Maximum Residue Limit (BMR) for pesticide diazinon, chlorphyrifos and profenofos
\end{abstract}

\section{Keywords : carddetection, pesticide, recidu, vegetables, Spectrophotometry}

\section{PENDAHULUAN}

Sayuran adalah tanaman hortikultura yang mempunyai nilai ekonomis tinggi, merupakan salah satu kebutuhan pokok masyarakat sebagai bahan pangan sumber vitamin dan mineral. (Anon, 2012; Anon, 2013). Sayuran merupakan bahan pangan yang cukup tinggi kontaminasi pestisidanya. Oleh karenanya sebagai konsumen harus mewaspadai dan memperhatikan karakteristik dari masing-masing jenisnya (Anon, 2013; Indraningsih, 2006; Anon, 2014). Di lapangan, biasanya petani memberikan perlakuan berbeda-beda terhadap masing-masing buah dan sayuran. Sebagai contoh sayuran jenis kol, petai, brokoli, kembang kol, buncis, paprika, kacang panjang, tomat, cabai, bawang dan kapri cukup tinggi kontaminasi pestisidanya karena jenis tanaman ini sangat rentan terhadap serangan serangga dan jamur sehingga para petani sering menyemprotkan insektisida dan fungisida pada sayuran tersebut. Selain itu sayuran tersebut biasanya dimasak tanpa di kupas sehingga kemungkinan terbawanya pestisida yang menempel di permukaan sayuran sangat besar, apalagi bila konturnya berlekuk seperti brokoli dan kembang kol. Karena kontur yang berlekuk menyebabkan pestisida melekat lebih erat dan susah larut saat di cuci (Anon, 2014; Indraningsih dan Yuningsih. 1995). 
Jenis insektisida yang umum digunakan di Indonesia adalah golongan organoklor, organofosfor, dan karbamat. Insektisida organoklorin memiliki toksisitas dan persistensi tinggi secara kimia, tetapi kurang efektif dan stabilitasnya dalam lingkungan ditandai dengan efek residu yang lama. Karena stabilitasnya yang lama, sehingga apabila digunakan akan berada dalam lingkungan cukup lama yaitu sekitar 15 tahun, dan bahkan mungkin lebih dari 100 tahun (Novizan. 2002; Indraningsih, 2006). Penggunaan insektisida dengan bahan aktif senyawa karbon berklor seperti dieldrin, toxapen dan DDT serta insektisida yang berbahan aktif senyawa fosfor seperti diazinon dan malation sudah mulai digunakan sejak pemberlakuan program intensifikasi pangan sekitar tahun 1970 sampai 1980-an.

Batas Maksimum Residu (BMR), adalah konsentrasi residu yang diperbolehkan berada dalam atau pada bahan pangan pada saat dipasarkan, dinyatakan dalam mg/kg (ppm) dan keberlakuannya di suatu Negara ditetapkan secara hukum. Pestisida merupakan racun bagi kehidupan sehingga mampu membunuh semua kehidupan yang ada, memiliki sifat yang tidak mudah hilang dan mempengaruhi kesehatan kehidupan maupun lingkungan, yang meninggalkan residu di dalam tanah dengan kekuatan hingga berpuluh-puluh tahun (Wiralaga, 2004; Novizan. 2002; Anon, 2014).

Banyak kalangan ingin mengetahui mengenai berapa banyak jumlah pestisida yang terdapat pada buah dan sayuran yang akan mereka konsumsi. Pentingnya pengujian residu pestisida pada makanan dan sayuran secara kualitatif dan kuantitatif dapat dilakukan dengan beberapa alat pengukuran seperti kartu pendeteksi residu pestisida maupun dengan Gas Chromatography Mass Spectrophotometry.

\section{METODE PENELITIAN}

Sampel sayuran diambil di beberapa petani yang membudidayakan sayuran di kecamatan Mengwi dan Kecamatan Petang. Sampel diambil di petani sebanyak masing-masing $2 \mathrm{~kg}$ dari 16 jenis sayuran yang di tanam oleh petani. Pengujian residu pestisida terhadap sayuran dilakukan mulai bulan April- Oktober 2020. Analisis sampel dilakukan sebanyak 2 kali ulangan, sehingga diperoleh sebanyak 32 sampel uji dan data yang diperoleh dianalisis secara diskriptif dengan menampilkan Tabel dan Gambar. Pengujian sampel terhadap residu pestisida dilakukan dengan metoda standar analisis kontaminasi pestisida dari Prosedur Pengujian Pestisida Dengan Kartu Pendeteksi (Pesticide Detection Cards) sesuai prosedur Association of Official Analitical Chemist (AOAC., 2004) dan Standar Nasional Indonesia (Nur et al., 1989)

\section{HASIL DAN PEMBAHASAN \\ Residu Pestisida Pada Sayuran}

Hasil pengujian secara kualitatif menunjukan bahwa 32 sampel yang diuji residu pestisidanya, 26 sampel tidak ditemukan mengandung residu pestisida golongan organofosfor dan organoklorin dan 6 sampel sayuran terindikasi positif mengandung residu pestisida). Pada Tabel 1 disajikan Residu 
pestisida secara kualitatif pada berbagai jenis

sayuran

Tabel 1. Pengujian Residu Pestisida secara Kualitatif pada Berbagai Jenis Sayuran

\begin{tabular}{llllllll}
\hline No & Jenis Komoditi & Sampel 1 & Sampel 2 & No & Jenis Komoditi & Sampel 1 & Sampel 2 \\
\hline 1 & Kangkung & Negatif & Negatif & 9 & Buncis & Negatif & Negatif \\
2 & Terong & Negatif & Negatif & 10 & Bayam Merah & Negatif & Negatif \\
3 & Timun Jepang & Negatif & Negatif & 11 & Daun Singkong & Negatif & Negatif \\
4 & Kacang & Positif & Positif & 12 & Sawi hijau & Negatif & Negatif \\
& Panjang & & & & & Negatif & Negatif \\
5 & Wortel & Negatif & Negatif & 13 & Pokcay & Negatif & Negatif \\
6 & Cabai Besar & Negatif & Negatif & 14 & Asparagus & Negatif & Negatif \\
7 & Cabai Rawit & Positif & Positif & 15 & Tomat & Negatif & Negatif \\
\hline
\end{tabular}

Berdasarkan struktur kimianya insektisida dapat dikelompokkan menjadi 3 kelompok yaitu organoklorin, organofosfor dan karbamat. Insektisida organoklorin terdiri atas karbon, klorin, hidrogen dan kadang-kadang oksigen, organoklorin dapat menyebabkan polusi terhadap lingkungan karena sifatnya yang persisten dalam tanah (Muriatikum dan Maria, 2006).

\section{Residu Diazinon pada Sayuran}

Hasil pengujian menunjukan bahwa dari 32 sampel yang diuji residu pestisidanya, Sebanyak 30 sampel sayuran tidak mengandung dan sebanyak 2 sampel mengandung diazinon yaitu sayuran sawi putih sampel 1 sebesar 0,015 ppm dan sawi putih sampel 2 sebesar 0,024 ppm. Pada Tabel 2 disajikan Residu Pestisida Diazinon pada berbagai jenis sayuran.

Residu pestisida Diazinon tidak saja ditemukan pada komoditi buah dan sayuran, tetapi juga ditemukan pada susu dijawa Barat sebesar 0,008 ug/kg, di Jawa Timur 0,0018 ug/kg dan pada daging di Jawa Barat sebesar 0,062 mg/kg (Indraningsih, 2006). Sementara Wiralaga (2004), menyatakan bahwa kadar residu pestisida pada tomat dan kubis yang ditanam pada musim kemarau lebih tinggi dibandingkan apabila di tanam pada musim penghujan.

\section{Residu Klorfirifos Pada Sayuran}

Hasil pengujian menunjukan bahwa Sebanyank 29 sampel sayuran tidak mengandung klorfirifos dan sebanyak 3 sampel mengandung resiidu pestisida kllorfirifos yaitu sayuran cabe rawit (sampel 1) dan cabe rawit (sampel 2 masing-masing sebesar 0,052 ppm dan 0,056 ppm serta pada kacang panajang hanya (sampel 1) yang mengandung residu pestisida klorfirifos sebesar 0,082 ppm. Pada Tabel 3 dapat dilihat residu pestisida klorin pada sayuran 


\section{Tabel 2. Residu Pestisida Diazinon Pada Berbagai Jenis Sayuran (ppm)}

\begin{tabular}{|c|c|c|c|c|c|}
\hline Komoditi & sampel 1 & sampel 2 & $\begin{array}{l}\text { BMR (ppm) } \\
\text { (PERMENTAN No : } 88 \\
\text { /Permentan/PP.340/12/2011) }\end{array}$ & $\begin{array}{l}\text { Indikasi } \\
\text { Kontamin } \\
\text { asi }\end{array}$ & $\begin{array}{l}\text { Persentase } \\
\text { Kontaminasi } \\
(\%)\end{array}$ \\
\hline Kangkung & $\mathrm{ttd}$ & $\mathrm{ttd}$ & 0,1 & Negatif & 0 \\
\hline Terong & $\operatorname{ttd}$ & $\mathrm{ttd}$ & 0,5 & Negatif & 0 \\
\hline Timun Jepang & $\mathrm{ttd}$ & $\mathrm{ttd}$ & 0,1 & Negatif & 0 \\
\hline Kacang Panjang & $\operatorname{ttd}$ & $\operatorname{ttd}$ & 0,1 & Negatif & 0 \\
\hline Wortel & $\operatorname{ttd}$ & $\operatorname{ttd}$ & 0,1 & Negatif & 0 \\
\hline Cabai Besar & $\operatorname{ttd}$ & $\operatorname{ttd}$ & 0,1 & Negatif & 0 \\
\hline Cabai Rawit & $\operatorname{ttd}$ & $\operatorname{ttd}$ & 0,5 & Negatif & 0 \\
\hline Sawi putih & 0,015 & 0,024 & 0,1 & $<\mathrm{BMR}$ & 100 \\
\hline Buncis & $\operatorname{ttd}$ & $\operatorname{ttd}$ & 0,1 & Negatif & 0 \\
\hline Bayam Merah & $\operatorname{ttd}$ & $\operatorname{ttd}$ & 0,5 & Negatif & 0 \\
\hline Daun Singkong & $\operatorname{ttd}$ & $\operatorname{ttd}$ & - & Negatif & 0 \\
\hline Sawi hijau & $\operatorname{ttd}$ & $\mathrm{ttd}$ & - & Negatif & 0 \\
\hline Pokcay & $\operatorname{ttd}$ & $\operatorname{ttd}$ & - & Negatif & 0 \\
\hline Asparagus & $\operatorname{ttd}$ & $\operatorname{ttd}$ & - & Negatif & 0 \\
\hline Tomat & $\operatorname{ttd}$ & $\operatorname{ttd}$ & 0,5 & Negatif & 0 \\
\hline Bayam & $\operatorname{ttd}$ & $\mathrm{ttd}$ & - & Negatif & 0 \\
\hline
\end{tabular}

Keterangan : ttd=tidak terdeteksi, $\mathrm{BMR}=$ Batas Maksimum Residu

Tabel 3. Residu Pestisida Khlofirifos pada Sayuran

\begin{tabular}{|c|c|c|c|c|c|c|}
\hline Komoditi & sampel 1 & sampel 2 & $\begin{array}{l}\text { BMR }(\mathrm{mg} / \mathrm{kg}) \\
\text { (PERMENTAN No : } \\
\text { /Permentan/PP.340/12/2011) }\end{array}$ & 88 & $\begin{array}{l}\text { Indikasi } \\
\text { Kontaminasi }\end{array}$ & $\begin{array}{l}\text { Persentase } \\
\text { Kontaminasi } \\
(\%)\end{array}$ \\
\hline Kangkung & $\mathrm{ttd}$ & $\mathrm{ttd}$ & 0,1 & & Negatif & 0 \\
\hline Terong & $\operatorname{ttd}$ & $\operatorname{ttd}$ & 0,5 & & Negatif & 0 \\
\hline Timun Jepang & $\operatorname{ttd}$ & $\operatorname{ttd}$ & 0,1 & & Negatif & 0 \\
\hline Kacang Panjang & 0,082 & $\operatorname{ttd}$ & 0,1 & & $<\mathrm{BMR}$ & 50 \\
\hline Wortel & $\operatorname{ttd}$ & $\operatorname{ttd}$ & 0,1 & & Negatif & 0 \\
\hline Cabai Besar & $\operatorname{ttd}$ & $\operatorname{ttd}$ & 0,1 & & Negatif & 0 \\
\hline Cabai Rawit & 0,052 & 0,056 & 0,5 & & $<\mathrm{BMR}$ & 100 \\
\hline Sawi putih & $\operatorname{ttd}$ & $\operatorname{ttd}$ & 0,1 & & Negatif & 0 \\
\hline Buncis & ttd & $\operatorname{ttd}$ & 0,1 & & Negatif & 0 \\
\hline Bayam Merah & $\operatorname{ttd}$ & $\operatorname{ttd}$ & 0,5 & & Negatif & 0 \\
\hline Daun Singkong & ttd & $\operatorname{ttd}$ & & & Negatif & 0 \\
\hline Sawi hijau & $\operatorname{ttd}$ & $\operatorname{ttd}$ & - & & Negatif & 0 \\
\hline Pokcay & ttd & $\operatorname{ttd}$ & - & & Negatif & 0 \\
\hline Asparagus & $\operatorname{ttd}$ & $\operatorname{ttd}$ & - & & Negatif & 0 \\
\hline Tomat & ttd & $\operatorname{ttd}$ & 0,1 & & Negatif & 0 \\
\hline Bayam & ttd & ttd & - & & Negatif & 0 \\
\hline
\end{tabular}

Keterangan : ttd=tidak terdeteksi, BMR=Batas Maksimum Residu

Klorpirifos, merupakan insektisida nonsistemik, diperkenalkan tahun 1965, serta bekerja sebagai racun kontak, racun lambung, dan inhalasi. Dampak penggunaan pestisida terhadap lingkungan sangat ditentukan oleh efektivitas pestisidanya (Hidayat, et al., 2013; Anonimus 2012; (Mukhlis et al., 2011; Sawyer et al., 1990).

\section{Residu Profenofos Pada Sayuran}


Hasil pengujian menunjukan bahwa

Sebanyak 30 sampel tidak mengandung profenofos dan 2 sampel sayuran mengandung residu pestisida profenofos yaitu pada sayuran sawi putih sampel 1 dan sawi putih sampel 2 sebesar 0,048 ppm dan 0,029 ppm. Pada Tabel 4 disajikan Residu Pestisida Profenofos pada Jenis Sayuran.

\section{Tabel 4. Residu Pestisida Profenofos pada Jenis Sayuran}

\begin{tabular}{|c|c|c|c|c|c|}
\hline Komoditi & sampel 1 & Sampel 2 & $\begin{array}{l}\text { BMR }(\mathrm{ppm}) \\
\text { (PERMENTAN No : } 88 \\
\text { /Permentan/PP.340/12/2011) }\end{array}$ & $\begin{array}{l}\text { Indikasi } \\
\text { Kontaminasi }\end{array}$ & $\begin{array}{c}\text { Persentase } \\
\text { Kontaminasi } \\
(\%)\end{array}$ \\
\hline Kangkung & $\overline{\mathrm{ttd}}$ & $\overline{\mathrm{ttd}}$ & 0,1 & Negatif & 0 \\
\hline Terong & $\mathrm{ttd}$ & $\mathrm{ttd}$ & 0,5 & Negatif & 0 \\
\hline Timun Jepang & $\operatorname{ttd}$ & $\operatorname{ttd}$ & 0,1 & Negatif & 0 \\
\hline Kacang Panjang & $\operatorname{ttd}$ & ttd & 0,1 & Negatif & 0 \\
\hline Wortel & $\operatorname{ttd}$ & $\operatorname{ttd}$ & 0,1 & Negatif & 0 \\
\hline Cabai Besar & $\operatorname{ttd}$ & ttd & 0,1 & Negatif & 0 \\
\hline Cabai Rawit & $\operatorname{ttd}$ & $\operatorname{ttd}$ & 0,5 & Negatif & 0 \\
\hline Sawi putih & 0,048 & 0,029 & 0,1 & Negatif & 100 \\
\hline Buncis & $\operatorname{ttd}$ & $\operatorname{ttd}$ & 0,1 & Negatif & 0 \\
\hline Bayam Merah & $\operatorname{ttd}$ & $\operatorname{ttd}$ & 0,5 & Negatif & 0 \\
\hline Daun Singkong & $\operatorname{ttd}$ & $\operatorname{ttd}$ & - & Negatif & 0 \\
\hline Sawi hijau & $\operatorname{ttd}$ & $\operatorname{ttd}$ & - & Negatif & 0 \\
\hline Pokcay & $\operatorname{ttd}$ & $\operatorname{ttd}$ & - & Negatif & 0 \\
\hline Asparagus & ttd & ttd & - & Negatif & 0 \\
\hline Tomat & $\mathrm{ttd}$ & $\operatorname{ttd}$ & 0,1 & $<$ BMR & 0 \\
\hline Bayam & td & $\mathrm{ttd}$ & 0,1 & Negatif & 0 \\
\hline
\end{tabular}

Keterangan: ttd=tidak terdeteksi, $\mathrm{BMR}=$ Batas Maksimum Residu

Insektisida organofosfor mengikuti perkembangan organoklorin. Organofosfor selalu mengandung fosfor dan dapat diidentifikasi oleh S-P atau O-P. (Wiralaga, 2004; Sawyer et al., 1990). Profenofos digunakan untuk mengendalikan berbagai serangga hama (terutama Lepidoptera) dan tungau (Tarumingkeng, 1977). Hasil pengujian menunjukan bahwa 32 sampel yang diuji residu pestisidanya, 26 sampel (8125\%) tidak ditemukan mengandung residu pestisida golongan organofosfor dan organoklorin dan 6 sampel sayuran $(18,75)$ terindikasi positif mengandung residu pestisida, 30 sampel sayuran $(93,75 \%)$ tidak mengandung residu pestisida diazinon dan sebanyak 2 sampel (6,25\%) mengandung diazinon, 29 sampel sayuran (90,63\%) tidak mengandung residu pestisida klorfirifos dan sebanyak 3 sampel (9,37\%) mengandung resiidu pestisida kllorfirifos dan sebanyak 30 sampel (93,75\%) tidak mengandung residu pestisida profenofos dan 2 sampel sayuran (6,25\%) mengandung residu pestisida profenofos. 


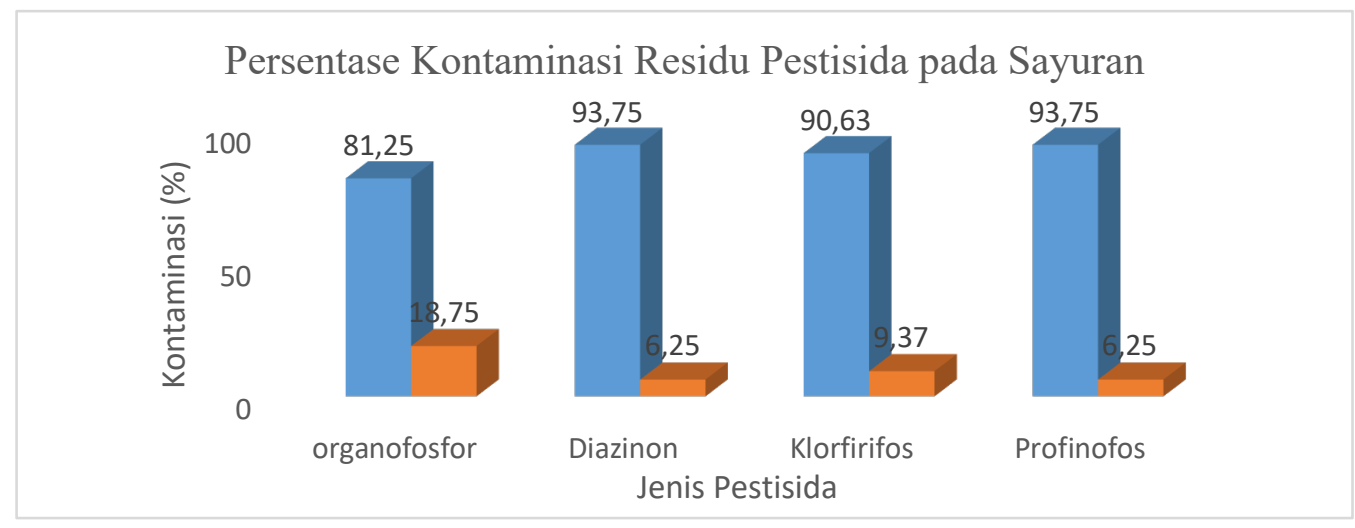

Gambar 1. persentase kontaminasi residu pestisida pada sayuran

\section{KESIMPULAN}

Hasil pengujian menunjukan bahwa Sebanyak 30 sampel sayuran $(93,75 \%)$ tidak mengandung diazinon dan sebanyak 2 sampel (6,25\%) mengandung diazinon yaitu sayuran sawi putih sampel 1 sebesar $0,015 \mathrm{ppm}$ dan sawi putih sampel 2 sebesar 0,024 ppm. Sebanyank 29 sampel sayuran $(90,63 \%)$ tidak mengandung klorfirifos dan sebanyak 3 sampel (9,37\%) mengandung resiidu pestisida kllorfirifos Sebanyak 30 sampel (93,75\%) tidak mengandung profenofos dan 2 sampel sayuran $(6,25 \%)$ mengandung residu pestisida profenofos yaitu pada sayuran sawi putih sampel 1 dan sawi putih sampel 2 sebesar $0,048 \mathrm{ppm}$ dan 0,029 ppm. Menurut PERMENTAN No: 88 /Permentan/PP.340/12/2011 dari hasil pengujian ini semua sampel berada di bawah Batas Maksimum Residu (BMR) pestisida diazinon, klorfirifos maupun profenofos

\section{UCAPAN TERIMA KASIH}

Ucapan terima kasih kami sampaikan kepada Rektor Universitas Udayana melalui Ketua Lembaga Penelitian dan Pengabdian Kepada Masyarakat Universitas Udayana atas fasilitas dan bantuan pendanaan yang telah diberikan sehingga penelitian dan karya tulis kami bias diselesaikan tepat pada waktunya. Ucapan terimakasih juga kami sampaikan kepada Dekan Fakultas Teknologi Pertanian
Universitas Udayana atas dukungan moril dan fasilitas yang diberikan.

\section{DAFTAR PUSTAKA}

Anonimus, 2013. Majalah Dokter Kita Edisi 10 tahun VII, Oktober 2013. http://www.pusatbiologi.com/2013/12/akibatdan-dampak-penggunaan-pestisida.html

Anonimus, 2014. Waspadai Residu PESTISIDA pada Sayur dan Buah. http://id.wikipedia.org/wiki/Dampak lingkung an dari pestisida

A.O.A .C .2004 . Official Methods of Analysis of Association of Official Analytical Chemist

Hidayat N, Anwar D, Erniwati I, 2013. Identifikasi Residu Pestisida Chlorfirifos dan Profenofos pada Bawang Merah (Allium ascalonium) di Pasar Terong dan Lotte Mart Kota Makasar.

Indraningsih dan Yuningsih . 1995 . Residu pestisida pada bermacam-macam sampel diagnosis

di bagian Toksikologi BALITVET dari tahun 19841995.Prosiding Seminar Nasional Peternakan dan Veteriner . Pusat Penelitian dan Pengembangan Peternakan . Badan LitBang Pertanian. Departemen Pertanian. Bogor, 1996.

Indraningsih, 2006. Sumber Kontaminasi dan Penanggulangan Residu Pestisida pada Pangan Produk Peternakan: Suatu Tinjauan. Balai Penelitian Veteriner, Bogor. Wartazoa v 16 (2). Muriatikum dan Maria R. 2006. Pemeriksaan Kontaminasi Pestisida dalam Komoditi Cabai 
Merah Besar dan Cabai Merah Keriting di Beberapa Kota dalam Upaya Penentuan BMR. Media Litbang, Kesehatan XVI . No 3.

Nur, M Anwar dan Adijuwana .1989. Teknik Pemisahan dalam Analisis. Biologis. PAU. Ilmu Hayat. IPB, Bogor

Novizan. 2002. Kiat Membuat dan Mengatasi Pestisida Ramah Lingkungan. Agro Media. 1(1):3-5

Sawyer LD, Mohan BM, Newsome WH, Parker GA. 1990. Pesticide and Industrial Chemical
Residue in Official Analitycal Chemist (AOAC) vol $1.15^{\text {th }}$ Edition, Virginia 22201. USA.

Wiralaga, A.Y.A. 2004. Residu Pestisida pada Tanaman Sayuran Dataran Tinggi. Jurnal Pengelolaan Lingkungan dan SDA 2 (1) Maret 31-35.

Tarumingkeng, R. 1977236 Pestisida Sebagai Alat Pengelolaan Hama Tanaman .Di dalam Wardojo, S. 1977. Aspek Pestisida di Indonesia .Edisi Khusus no. 3 . Lembaga Pusat Penelitian Pertanian Bogor 